\title{
Surface-velocity field of the northern Larsen Ice Shelf, Antarctica
}

\author{
R. A. Bindschidaler, M. A. Fahnestock, \\ Code 971, NASA/Goddard Space Flight Center, Greenbelt, MD 20771, U.S.A. \\ P. SKVARCA, \\ Instituto Antártico Argentino, Cerrito 1248, 1010 Buenos Aires, Argentina
}

T. A. SCAMBOS

National Snowe and Ice Data Center, University of Colorado, Boulder, CO 80309-0449, L.S.A.

\begin{abstract}
Three satellite images of the northern Larsen Ice Shelf are uscd to derive velocity fields for the periods $1975-86$ and 1986 89. Substantial increases in the speed of the ice between these periods are detected to a high degree of confidence. Ice which entered the ice shelf between Fothergill Point and Cape Worsley and ice from Drygalski Glacier has accelerated by approximately $15 \%$ over the measurement period. Ice from Bombardier and Dinsmoor Glacicrs also exhibits acceleration but by a lesser amount. These accelerations may be the result of either significant retreat experienced by the ice shelf during this period or warming in the Antarctic Peninsula region. Velocities measured by surface survey over a $15 \mathrm{~d}$ period in 1991 indicate a slower velocity than the image-derived velocities in the limited region of overlap. These differences appear to be systematic and may be the result of uncontrolled errors in the surface survey. Limited control of one image could also contribute to some of these differences.
\end{abstract}

\section{INTRODUCTION}

The Antarctic Peninsula has been identified as an area experiencing atmospheric warming in recent years (Morrison, 1990). Doake and Vaughan (1991) have documented, by satellite imagery collected between 1974 and 1989, the disintegration of Wordie Ice Shelf on the western side of the peninsula and have suggested that this warming is responsible for the demise of this ice shelf.

The northern part of the Larsen Ice Shelf discussed in this paper lies approximately $600 \mathrm{~km}$ north-northeast of Wordie Ice Shelf and on the eastern side of the Antarctic Pcninsula. With a more complete sct of satellite images, the retreat history of this region of Larsen Ice Shelf has also becn documented (Skvarca, 1993). The amount of retreat increases with distance north of Lindenberg Island (Fig. 1). The most dramatic retreat has been a $20 \mathrm{~km}$ recession of the ice front in Larsen Inlet in just 3 years. The retreat can be seen by comparing the ice fronts on Figures 1, 2 and 3.

In this paper, we use three of the images in the Larsen Ice Shelf time series to investigate the velocity field of this ice shelf over a 14 ycar period. Digital images were used to take advantage of recent cross-correlation techniques for the derivation of the velocity fields. Comparison between velocity fields averaged over different periods suggest that the ice shelf is accelerating.

\section{TECHNIQUES}

The method of using cross-correlation to track features in sequential imagery has been described elsewhere (Scambos and others, 1992). Here, our technique is being applied to imagery of three different resolutions. 'The most recent image is a Landsat Thematic Mapper (TM) image collected on 5 November 1989. The second image is a Landsat MSS image collected on 1 March 1986 (Fig. 1). The oldest image is a Kosmos Kate-200 image collected on 3 October 1975.

The two Landsat images were available in a digital format on computer tapc and were processed by us first to eliminate, scan-line noise in each spectral band. Gener-ation of a first principal-component image reduced noise still further. 'l'he Kosmos image was only available as a photographic negative. The negative was printed and scanned to generate a digital version necessary for the tracking software. The respective pixel dimension of each digital image is: Kosmos, $77 \mathrm{~m}$; MSS, $57 \mathrm{~m}$; and ' $\mathrm{I} M, 28.5 \mathrm{~m}$.

Given the various resolutions of the images used, this study supplied a useful test of the software's capabilities for handling different image resolutions and was one of the motivations for undertaking the study. The crosscorrelation technique is much more adept at tracking subtle or poorly resolved features than pixel-picking methods. The long time periods involved provide an 


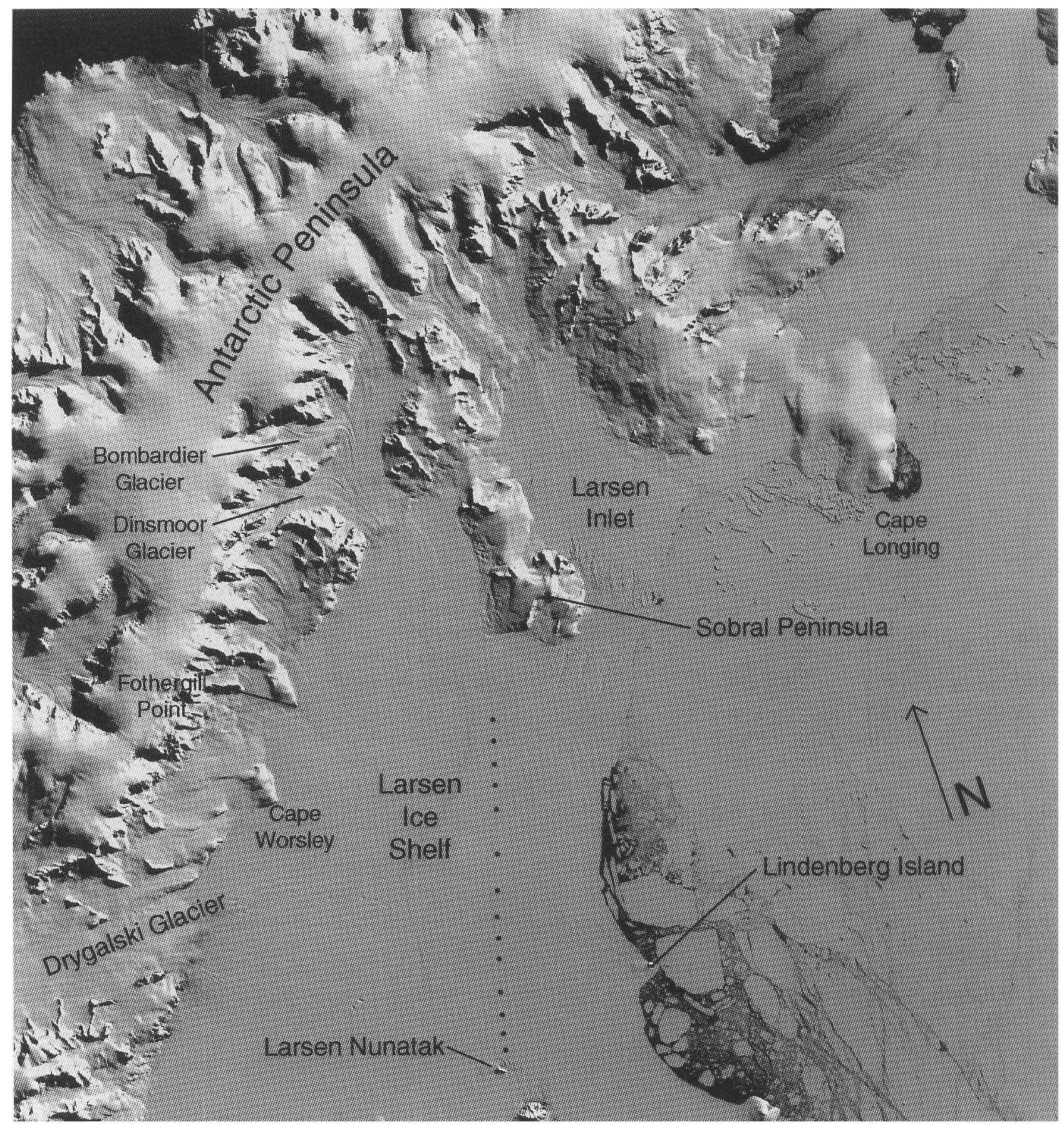

Fig. 1. Landsat-MSS image of northern Iarsen Ice Shelf collected on 1 March 1986 and used as the reference image in this study. Locations of landmarks referred to in the text are indicated. Solid circles indicate positions of surveyed markers discussed in the text.

additional challenge to the software's ability to match features after many years of flow. As will be shown, the software performs well under these difficult circumstances.

To make measurements of feature displacements in separate images meaningful, the images must first be coregistered. We chose the MSS image as the control image and measured displacements backward in time to the Kosmos image and forward in time to the TM image. Because the MSS served as the control image, and the other images were resampled as part of the co-registration process, distances, when stated in pixel lengths, will always refer to the MSS pixel dimension, $57 \mathrm{~m}$. The sample axis of the MSS image (horizontal on Figures 1, 2 and 3 ) has an azimuth of $109^{\circ}$ from true north (determined from survey data described later).

In the case of the older image pair (Kosmos-MSS), 17 common control points were chosen on rock outcrops on three sides of the ice shelf, from Lindenberg Island clockwise around to Sobral Peninsula. Where possible, control points were chosen close to the ice shclf, at low elevation, to optimize the accuracy of the fit on the ice shelf and to minimize elcvation-induced distortion. A third-order polynomial was used to warp the Kosmos image to fit the MSS image. This polynomial matched the positions of the control points with an RSS residual of 0.84 pixels $(0.61$ pixels in $x$ (sample axis) and 0.5 pixels in $y$ (line axis)). Resampling during the warping process used a cubic convolution algorithm. 


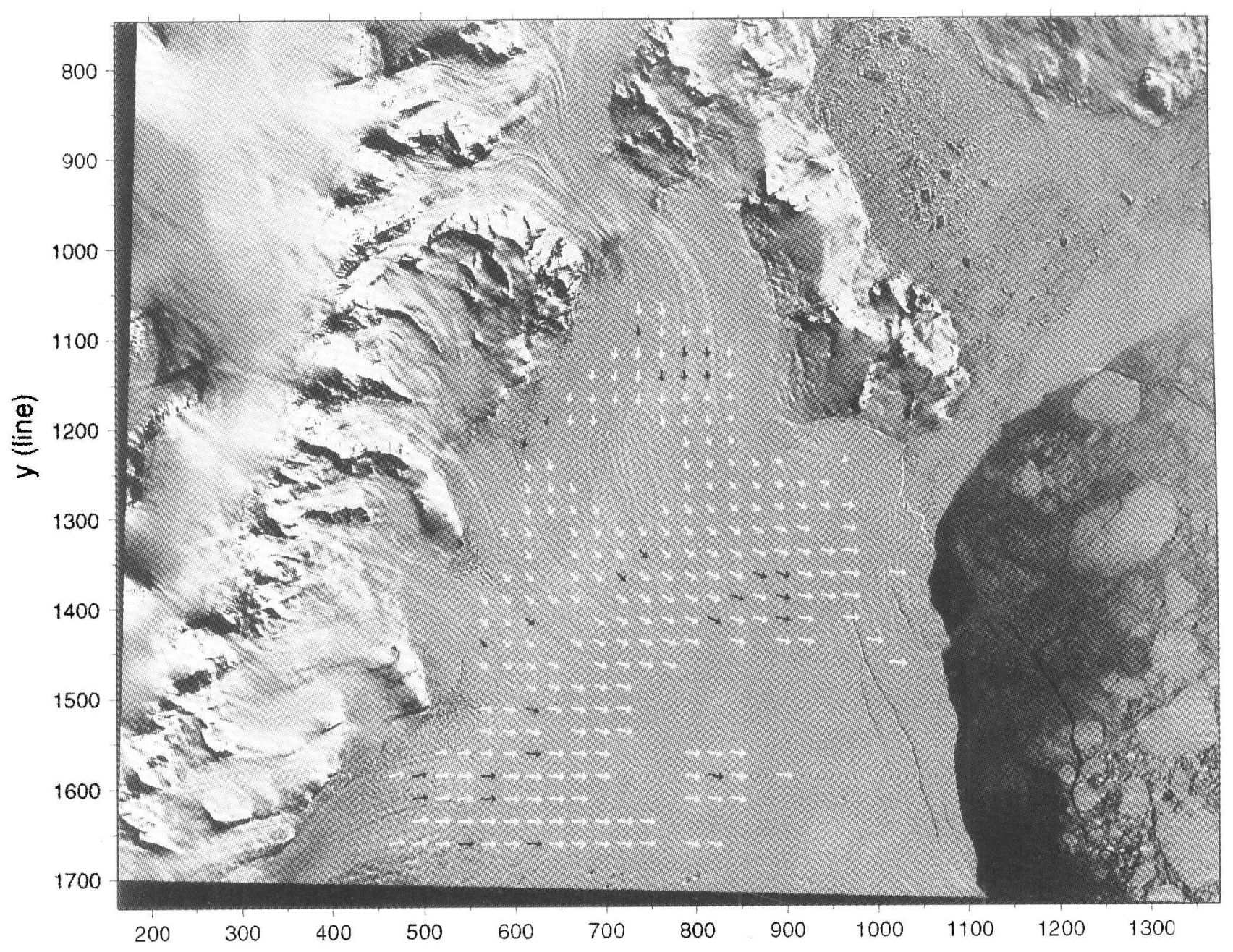

Fig. 2. Landsat-TM image collected on 5 November 1989 and used in this study. It has been resampled and warped to coregister with the MSS image (Fig. 1). As discussed in the text, the image does not extend far enough south to include either Lindenberg Island or Larsen Nunatak. Velocity field is derived from the MSS-TM image pair. Vector lengths correspond to actual displacements over the 3.68 year interval - vector tails are the centers of the reference areas in the MSS image and vector heads are the centers of the reference areas as located in the TM image. Black vectors are those in common with the Kosmos-MSS data set (Fig. 3; Table 1). Vector grid spacing is 25 pixels (1425 m). Coordinate system refers to MSSimage pixels by sample ( $x$ axis) and line (y axis).

In the case of the TM-MSS co-registration, the 'TM image did not extend far enough south to permit the use of either Larsen Nunatak or Lindenberg Island for coregistration control (see Fig. 2). Without the availability of these areas for control points for this image pair, coregistration errors can grow to the southeast. To hold extrapolation crrors in check, only a second-order warping polynomial was used and more control points (20) were chosen over a wider area than in the Kosmos image. This polynomial fitted the control points with an RSS of 1.02 pixels $(0.91$ pixels in $x$ and 0.47 pixels in $y$ ).

Once co-registercd, each pair of images (KosmosMSS and MSS-TM) was run through the crosscorrelation tracking software to generate a set of displacement vectors. The size of the reference area the subimage window whose features are to be matched in the search area of the second image) was taken to be $32 \times 32$ pixels, and the search area in the second image was taken to be $128 \times 128$ pixels. The grid spacing of reference areas was 25 pixcls $(1.425 \mathrm{~km})$. In each pair, the MSS served as the reference image and the Kosmos or
TM was the search image. By applying the software in this way, we located the same reference area (i.e. set of unique features) in both the older and newer images. This thrce-cpoch trajectory assisted greatly in judging the validity of three-epoch matches discussed later. A conservative value of the $1 \sigma$ accuracy of the crosscorrclation procedurc based on our work with other imagery is that the location of the features in the reference area can be identificd in the search image to \pm 0.5 pixels.

The software calculates a strength parameter of cach match but we have found, in practice, that the output file still has many spurious matches with high strengths and many weak matches that are, in fact, valid. The calculated displacement field was coherent enough to permit the easy identification of spurious matches and confirm weak matches based on surrounding velocity data and glaciological clues such as flow stripes and the positions of major tributary glaciers. Editing of the software's output file was done interactively on the computer screen using customized software that allowed the user to ficker between each image while viewing an 


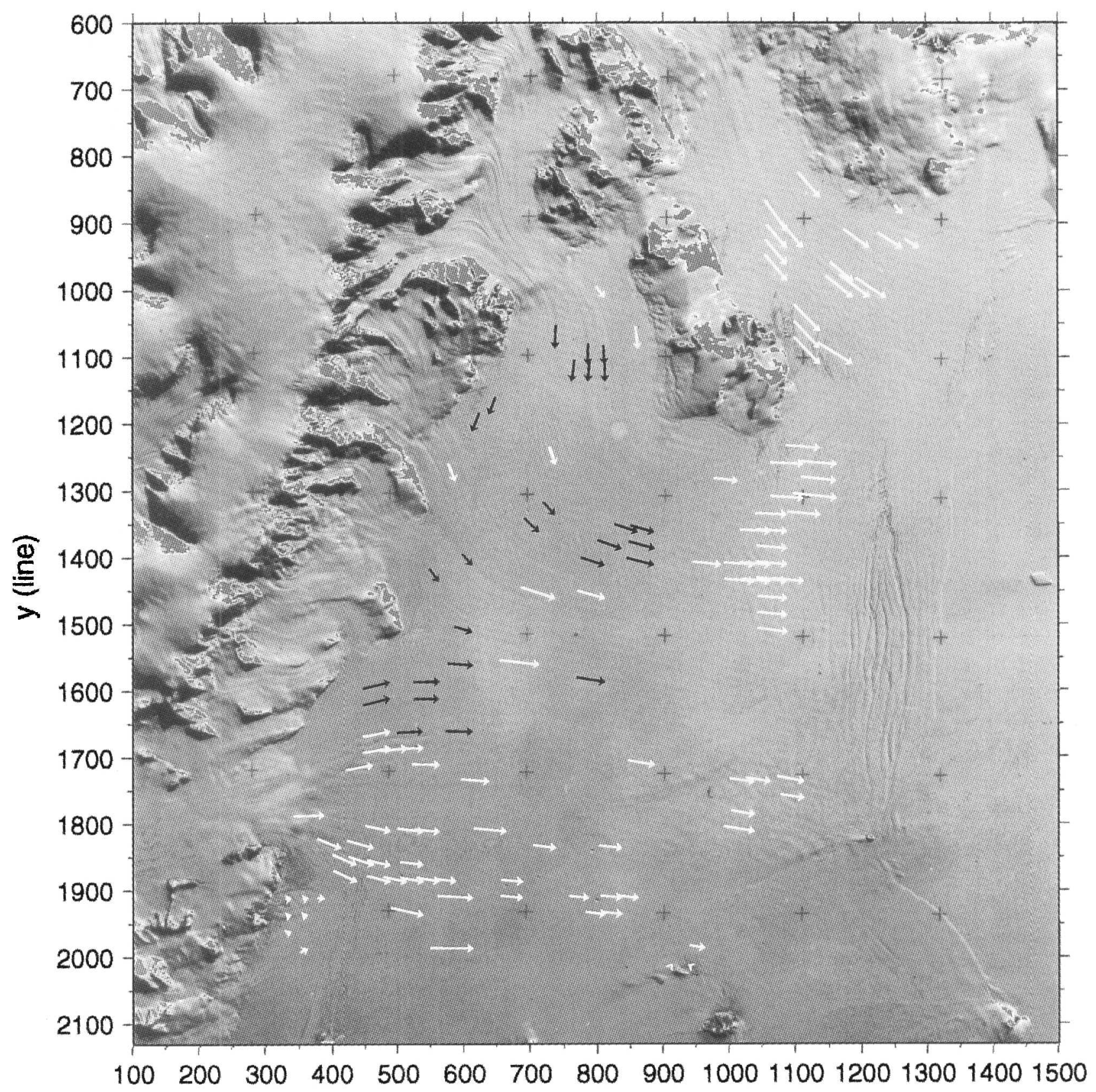

Fig. 3. Kosmos Kate-200 image collected on 3 October 1975 and used in this study. It has been resampled and warped to coregister with the MSS image (Fig. 1). Velocity field is derized from the Kosmos-MSS image pair. Vector lengths correspond to actual displacements over the 10.41 year interzal vector heads are the centers of the reference area in the MSS image and vector tails are the centers of the reference areas as located in the Kosmos image. Black vectors are those in common with the MSS-TM data set (Fig. 2; Table 1). Vector grid spacing is 25 pixels (1425 m). Coordinate system refers to MSS-image pixels by sample (x axis) and line (y axis).

overlay of the center points of all reference areas and their calculated trajectories (Fahnestock and others, 1992).

\section{IMAGE-DERIVED VELOGITY FIELDS}

Due to the higher resolution of the $\mathrm{IM}$ image and the shorter time period between the MSS and TM images (3.68 years), the sofware was able to produce a more complete and spatially coherent velocity data set than was possible for the older image pair. Figure 2 shows the edited velocity field of 244 vectors derived from this image pair. The length of the vector corresponds to the actual displacement of the reference-arca center. It shows the discharge of numerous glaciers feeding into the ice shelf and the gradual acceleration of this ice toward the ice front. Two regions are without velocity data. The first is the broad, featureless southeastern region where the lack of features prevented any opportunities for tracking. 'The other region is the area of longitudinal ridges near the top of the mapped grid. The orientation of the dominant ridges in this area prevented the software from finding acceptable maxima to the cross-correlations in the alongHlow direction. 
The \pm 0.5 pixcl uncertainty in measuring displacement converts to a relative speed error $1 \sigma)$ of $\pm 8 \mathrm{ma}^{-1}$. The accuracy due to co-registration adds an crror component to the absolute accuracy which varies because of the lack of control to the south and east. Near control points, the position crror of co-registration $( \pm 1.02$ pixels) converts to a speed uncertainty of $\pm 16 \mathrm{ma}$. This error increases with distance from control, reaching a maximum at the southeast corner, where, based on the polynomial coeflicients used in the warping, we estimate it may be as large as $\pm 50 \mathrm{ma}^{-1}$. Thus, the crror in the absolutc speed of the MSS-TM data set ranges from $\pm 18 \mathrm{ma}$ near rock to $\pm 51 \mathrm{ma}^{-1}$ at the southeast cxtreme.

The velocity field derived from the Kosmos MSS image pair was more sparse but still contains 135 points Fig. 3). The sparseness is a combined result of the longer time period ( 10.41 years) and the poorer resolution of this image pair. Enough matches were achicved to show the same basic pattern of flow. The more seaward extent of the ice shelf in this earlier period allowed some velocities to be measured beyond the icc-front position in 1989 . including in Larsen Inlet where catastrophic retreat occurred between 1986 and 1989. The maximum speed in the central part of the ice shelf occupying Larsen Inlet was $309 \mathrm{ma}^{\text {l }}$ over this interval. The extension of coverage to the south shows the effect of Drygalski Glacier as it spreads laterally once it enters the ice shelf. Clearly, this glacier is a major tributary of the northern Larsen Ice Shclf.

One advantage of the longer time period between the Kosmos and MSS images is that the uncertainties in velocity measurements are decreased. The relative accuracy $(1 \sigma)$ is $\pm 3 \mathrm{~m}$ a . The co-registration-induced component of error is $\pm 5 \mathrm{ma}{ }^{1}$, which, due to the thirdorder fit, varies throughout the image. However, due to the presence of control on Lindenberg Island and Larsen Nunatak, this error cannot grow in an unbounded fashion as with the MSS-TM data set. We suggest the error of the absolute specd in the Kosmos-MSS data set is $\pm 6 \mathrm{ma}^{-1}$.

The error in velocity azimuth depends on the position uncertainty of the feature match and the magnitude of the displacement. As a guide, we use a typical velocity of $200 \mathrm{~m} \mathrm{a}^{1}$ and use the position uncertainty of \pm 0.5 pixel stated above. With these numbers, the typical $1 \sigma$ error in velocity azimuth is $\pm 2^{\circ}$ for the recent MSS-TM data set and $\pm 0.7^{\circ}$ for the older, but longer duration, KosmosMSS data set. Of course, these velocity measurements do not represent instantaneous directions or speeds but are arcrages over the corresponding time interval. The smoothness of the velocity fields in Figures 2 and 3 supports these accuracy estimates of velocity magnitude and azimuth.

\section{COMPARISON OF IMAGE-DERIVED VELOCITY FIELDS}

At 27 grid points, there were velocities from both the earlier and later time periods (Figs 2 and 3). Comparisons were made at most of these points between the measured velocity during the more recent MSS-TM time period and a prediction of the velocity bascd on the velocity during the older Kosmos-MSS period corrected for longitudinal strain ratc and rotation rate (Table 1). The values for longitudinal strain rate and rotation rate were derived from the MSS-TM data set, because it was more complete spatially, permitting the calculation of local values of these two parameters at nearly all of the common points using a centered-difference scheme. At six locations (noted in Table 1), the longitudinal strain rate and rotation rate had to be calculated centered at an adjacent grid point. In two cases (also noted in Table 1), data were insufficient for an estimate of these parameters. The data are arranged into five flow regions and are discussed in order below.

In the "Dinsmoor/Bombardier Glacier" area, the ice is compressing longitudinally and extending laterally. The six common points indicate a slight acceleration with a mean velocity increase of $11.3 \mathrm{~m} \mathrm{a}^{-1}$. The fact that there are six points in this region reduces the likelihood that the crror is due to the random component of the measurement. However, this advantage has only a minor impact on the test of significance, because the random component of measurement error is smaller than the systematic component, as discussed earlier. The $1 \sigma$ magnitude for testing the significance of this change is $\pm 17.1 \mathrm{ma}^{-1}$, which is already larger than the mean velocity increase. This corresponds to only a $49 \%$ confidence level in the significancc of this result. The change in velocity azimuth has a mean value of $-2.5^{\circ}$. The $1 \sigma$ magnitude for significance of this component is $\pm 2.1^{\circ}$-again near the $1 \sigma$ level of significance.

Two points in the margin of this flow have been separated out as "West Margin", because they are spatially distinct. Adjacent data were not present to calculate longitudinal strain rates and rotation rates. Nevertheless, the two data sets show the cxpected counter-clockwise rotation in azimuth as another glacier feeds into the ice shelf just north of Fothergill Point. The changes in velocities are negligible.

As the ice from Dinsmoor and Bombardier Glaciers moves past Sobral Peninsula, it flows into the region named here "Big Curve". The data in Table 1 show that this region has accelerated with a mean velocity increase of $29.9 \mathrm{~m} \mathrm{a}^{-1}$. This is greater than the $1 \sigma$ value of uncertainty $( \pm 17.0 \mathrm{ma}$ for eight data points) and can be assigned a $91 \%$ level of confidence. The significance of the mean change in azimuth, $4.1^{\circ}$, also is above $90 \%$.

The next region considered is the unnamed glacier that enters Larsen Ice Shelf between Fothergill Point and Cape Worsley. Two of the three points in this region show the largest velocity increases in this study. The mean velocity increase is $50.8 \mathrm{ma}^{-1}$, roughly equal to three times the $\sigma$ of $\pm 17.5 \mathrm{ma}^{-1}$ for three data points. These numbers imply a confidence level of over $99 \%$ but the fact that the longitudinal strain rates and rotation rates had to be calculated at adjacent grid points for two of the three points may also be responsible for some part of the indicated changes.

The final region, "Drygalski Glacier", corresponds to ice entering the ice shelf south of Cape Worsley. It is limited to the south by the extent of the TM image. Again, an accelcration is calculated with a mean vclocity increase of $29.1 \mathrm{ma}^{1}$ and, as with the "Big Curve" region, the statistical significance test has a $\sigma$ of $\pm 17.0 \mathrm{ma} \mathrm{a}^{-1} . \Lambda 91 \%$ confidence level can be assigned to 
this result. The changes in azimuth are small but consistent with straight flow.

$\Lambda$ s discussed above, the crrors in the absolute velocities are due primarily to possible systematic errors in the coregistration of image pairs. This crror would tend to cause a uniform error in a single direction across any pair of images. The separate regions in this velocity comparison flow in many different directions yet all (cxcept "West Margin") show acceleration. This fact reduces the likelihood that systematic errors are responsible for the accelerations and raises confidence that the measured accelerations between 1975 and 1989 are real.

\section{COMPARISON WITH GROUND SURVEY}

A ground survey of a single line of surface markers on Larsen Ice Shelf was conducted during November 1991 by personnel from the Instituto Antártico Argentino (see Fig. 1). This line extended from Larsen Nunatak to Sobral Peninsula with an average azimuth of $17^{\circ}$ from true north. Weather conditions during the first survey 15 November 1991) were very warm and made it impossible to close the survey by sighting to any fixed point on Sobral Peninsula. $15 \mathrm{~d}$ later, after conditions had improved, a second survey of this line was conducted and Sobral Peninsula was occupicd but no independently known positions could be tied into the survey to calculate absolute surveying errors.

Instrument precision can provide a partial estimate of errors. Angles between markers were measured with a Zeiss Th 2 theodolitc and actual misclosures suggest an error of \pm 2 " of arc. Distances between markers were measured with a $\mathrm{C}-1000$ tellurometer with a stated singlcmeasurement prccision of $0.05 \mathrm{ft}[1.5 \mathrm{~cm}]$ plus a scale error due to "atmospheric refractive-index determination and crystal-frequency drift" which is stated by the manufacturer to be "usually less than $5 \mathrm{ppm}$ ". The typical distance between markers was $2-4 \mathrm{~km}$, so we assume here a distance-measurement accuracy of $\pm 2.5 \mathrm{~cm}$. If these errors are treated as random (the scale error may not be), they will accumulate at the rate $\operatorname{sqrt}(N)$ where $N$ is the number of markers already surveyed along the traverse. From the orientation of the direction of the traverse relative to the azimuths of the marker's motion, the largest standard errors at the most distant marker

Table 1. Comparison of image-derived velocity data sets

\begin{tabular}{|c|c|c|c|c|c|c|c|c|c|c|c|}
\hline \multirow[b]{2}{*}{ Sample $(x)$} & \multirow[b]{2}{*}{ Line $(y)$} & \multicolumn{2}{|c|}{ Kosmos-MSS } & \multicolumn{2}{|c|}{$M S S-T M$} & \multirow[b]{2}{*}{$\begin{array}{l}\text { Longitudinal } \\
\text { strain rate }\end{array}$} & \multirow[b]{2}{*}{ Rotation rate } & \multirow[b]{2}{*}{$\begin{array}{l}\text { Predicted MSS- } \\
\text { TM speed }\end{array}$} & \multirow[b]{2}{*}{$\begin{array}{c}\text { Speed diff. } \\
\text { (meas.-pred.) }\end{array}$} & \multirow[b]{2}{*}{$\begin{array}{l}\text { Azimuth diff. } \\
\text { (meas.-pred.) }\end{array}$} & \multirow[b]{2}{*}{ Vater } \\
\hline & & $\begin{array}{c}\text { Speed } \\
1975-86\end{array}$ & $\begin{array}{l}\text { Azimuth } \\
1975-86\end{array}$ & $\begin{array}{c}\text { Speed } \\
\text { 1986-89 }\end{array}$ & $\begin{array}{l}\text { Azimuth } \\
1986-89\end{array}$ & & & & & & \\
\hline Pixel & Pixel & $\mathrm{ma}^{1}$ & o & $\mathrm{mat}^{1}$ & 0 & $\times 10^{3} \mathrm{a}$ & $\mathrm{a}^{\mathrm{l}}$ & $\mathrm{ma}^{1}$ & $\mathrm{ma}^{\prime}$ & 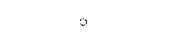 & \\
\hline \multicolumn{12}{|c|}{ Dinsmow Bombardier Glacier } \\
\hline $738^{\circ}$ & 1086 & 184.7 & 182.7 & 187.8 & 185.1 & -9.471 & 0.35 & 172.4 & 15.4 & -0.1 & $a$ \\
\hline 763 & 1136 & 173.5 & 187.6 & 182.7 & 180.5 & -1.034 & -0.25 & 172.2 & 10.5 & 5.3 & \\
\hline 788 & 1111 & 173.2 & 180.9 & 170.3 & 178.0 & -9.859 & -0.14 & 161.2 & 9.1 & -1.9 & \\
\hline 788 & 1136 & 156.7 & 184.6 & 164.7 & 177.2 & -3.151 & 0.30 & 153.2 & 11.5 & -5.3 & \\
\hline 813 & 1111 & 154.8 & 177.5 & 161.9 & 176.3 & -5.03 & -0.19 & 149.3 & 12.6 & 0.1 & \\
\hline 833 & 1336 & 152.4 & 180.6 & 158.0 & 135.3 & -4.839 & 0.35 & 147.2 & 8.8 & -2.4 & \\
\hline \multicolumn{12}{|l|}{ West Margin } \\
\hline 6.38 & 1186 & 151.1 & 201.6 & 159.5 & 191.9 & & & & 8.4 & -9.7 & b \\
\hline 613 & 1211 & 160.5 & 201.1 & 160.2 & 189.5 & & & & -0.3 & -11.6 & b \\
\hline \multicolumn{12}{|l|}{ Big Curve } \\
\hline 713 & 1361 & 165.6 & 133.7 & 199.6 & 133.7 & 7.493 & 0.53 & 174.3 & 25.3 & 3.7 & \\
\hline 738 & 1336 & 141.8 & 138.4 & 186.3 & 135.9 & 6.998 & $\cdots 0.59$ & 118.8 & 37.5 & 1.7 & \\
\hline 813 & 1411 & 205.2 & 108.3 & 242.6 & 112.6 & 3.945 & -0.46 & 210.9 & 31.7 & 7.5 & a \\
\hline 838 & 1386 & 206.8 & 109.1 & 243.4 & 110.8 & 2.607 & -0.42 & 210.6 & 32.8 & 4.7 & \\
\hline 863 & 1361 & 198.1 & 108.5 & 241.3 & 111.2 & 4.047 & 0.34 & 203.7 & 37.6 & 5.1 & \\
\hline 888 & 1361 & 201.1 & 105.6 & 245.5 & 109.1 & 2.968 & -0.37 & 205.3 & 40.2 & 6.1 & \\
\hline 888 & 1386 & 219.5 & 105.1 & 246.5 & 105.8 & 2.736 & -0.38 & 223.7 & 22.8 & 3.4 & \\
\hline 888 & 1411 & 233.1 & 104.6 & 251.5 & 102.7 & 4.561 & 0.37 & 240.6 & 10.9 & $0 . \overline{7}$ & \\
\hline \multicolumn{12}{|c|}{ Fothergill Point to Cape Worsley } \\
\hline 563 & 1436 & 130.4 & 143.3 & 159.3 & 135.9 & -0.011 & -0.09 & 130.4 & 28.9 & -6.8 & $\mathrm{a}$ \\
\hline 613 & 1411 & 119.6 & 139.5 & 183.3 & 131.4 & 1.183 & 0.01 & 118.6 & 64.7 & -8.2 & $\mathrm{a}$ \\
\hline 613 & 1511 & 150.6 & 107.0 & 220.6 & 107.8 & I0.544 & -0.41 & 161.8 & 58.8 & 3.7 & \\
\hline \multicolumn{12}{|c|}{ Dryalski Glacier } \\
\hline 488 & 1586 & 226.6 & 77.3 & 247.9 & 81.3 & $6.15 \overline{5}$ & 0.25 & 216.8 & 31.1 & 5.8 & a \\
\hline 488 & 1611 & 225.2 & 76.3 & 257.1 & 80.5 & -3.02 & 0.21 & 220.4 & 36.7 & 2.7 & a \\
\hline 538 & 1661 & 211.4 & 87.5 & 248.5 & 90.2 & -1.288 & 0.17 & 209.5 & 39.0 & 1.5 & \\
\hline 56.3 & 1586 & 217.6 & 89.1 & 247.6 & 90.9 & 4.279 & 0.20 & 224.2 & 23.4 & 3.2 & \\
\hline 563 & 1611 & 208.8 & 89.2 & 249.2 & 90.3 & 0.414 & 0.16 & 209.4 & 39.8 & 0.0 & \\
\hline 613 & 1561 & 206.6 & 94.4 & 237.9 & 96.9 & 7.382 & -0.19 & 217.3 & 20.6 & 3.8 & \\
\hline 613 & 1661 & 223.5 & 91.0 & 247.8 & 92.7 & 2.79 & 0.14 & 219.1 & 28.7 & 0.7 & \\
\hline 813 & 1586 & 235.5 & 99.0 & 253.5 & 100.4 & 2.602 & 0.02 & 239.8 & 13.7 & 1.3 & \\
\hline
\end{tabular}

Notes. a. Longitudinal strain rate and rotation ratc contered on adjacent grid point; b. Insufficient data to evaluate longitudinal strain rate and rotation rate. 

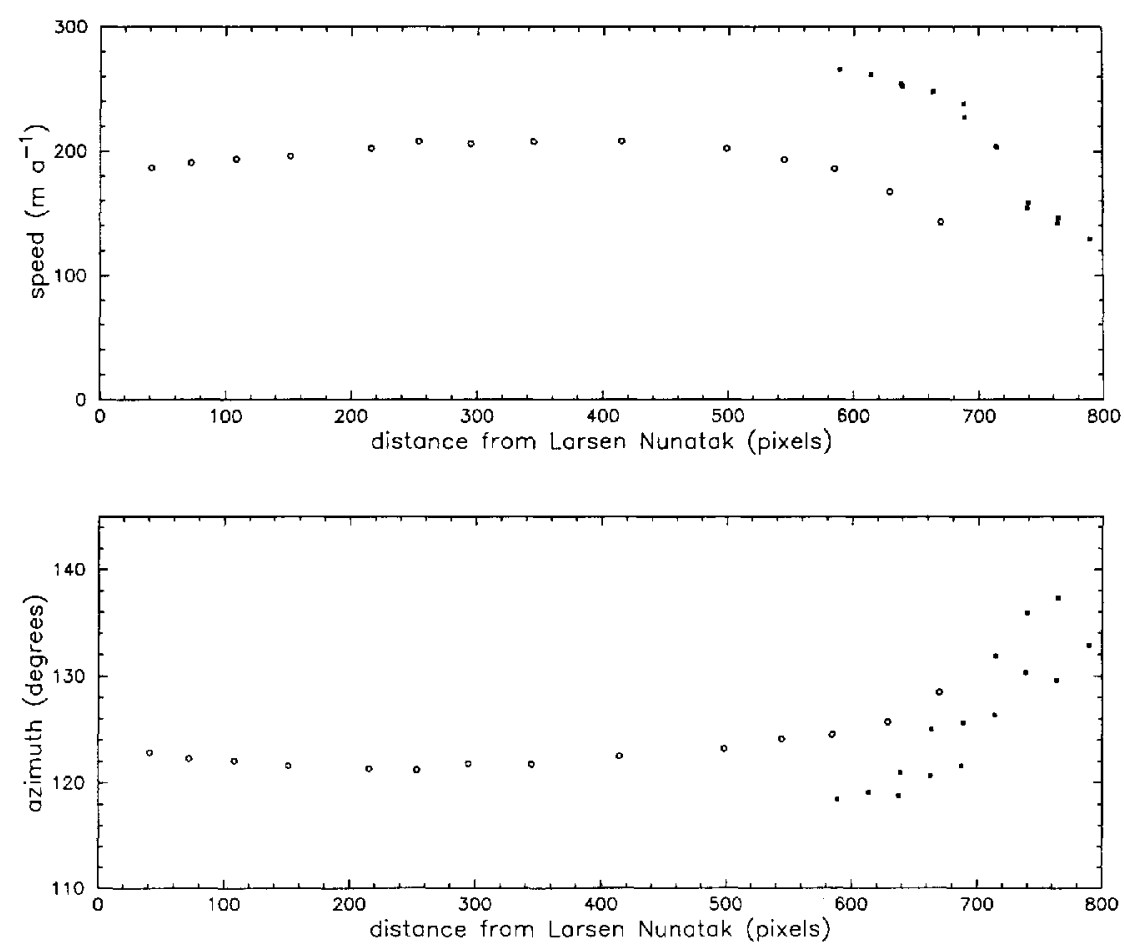

Fig. 4. Speed and azimuth along a line following the surface traverse from Larsen Nunatak toward Sobral Peninsula discussed in the text. Open circles are the surface-survey data (see Figure 1 for positions). Solid squares are image-derived velocity data from the MSS-TM data setwithin 25 pixels of the line, projecled orthogonally on to the line.

(P14) are $\pm 2 \mathrm{ma}^{-1}$ in speed and $\pm 1^{\circ}$ in azimuth.

While these facts leave unresolved the absolute accuracy of the velocities derived from the short-period survey, we nevertheless compare them with the imagederived data. Figure 4 compares the velocity data along the surveyed profile. Image-derived velocities within 25 pixels $(712.5 \mathrm{~m})$ of the surveycd profile have been projected orthogonally on to a profile that runs through the survey line. The few occurrences of two points at nearly the same profile distance on the MSS-TM profile are a result of the surveyed profile being nearly parallel (4) to the velocity grid. The difference between these pairs of points shows that the effect of longitudinal strain ratc is ncgligiblc for this comparison. Over the scgment of overlapping profiles, the profiles have the same shape but a rather consistent offset of about $75 \mathrm{~m} \mathrm{a}^{-1}$ in velocity and $6^{\circ}$ in azimuth. The relative smoothness of cach profile suggests small errors for each profile and the possible presence of a systematic error.

We have searched extensively for systematic crrors, without success. Given the smoothness of the survey profiles, the most obvious source of a systematic error in this data set is in the survey of the first point. It, however, was surveyed 13 separate times from two stationary points on Larsen Nunatak between 11 November and 6 December 1991 with a resulting speed consistent with the value obtained from the two ice-shelf traverse surveys.

The image data also were examined in a number of ways in a search for systematic errors. Different control points and polynomial orders for warping were tried. Differences always fell within the calculated errors stated above. An interesting spin-off investigation centered on the fact that a systematic shift of the MSS pixels by 5.5 pixels in the sample direction would bring both the velocity magnitude and azimuth into agreement with the groundsurvey data. This shift had to be limited to the ice shelf itself because control points on the rock were matched during the co-registration process. Thus, it would need to be an internal distortion within a limited area of the MSS image. Discussion with a mapping expert with vast experience using Landsat data for mapping and calibration from the beginning of the satellite serics stated catcgorically that internal distortion of this magnitude for Landsat data collected in the mid- to late 1980 s exceeded anything he had ever seen or heard of and was, therefore, highly unlikely (personal communication from A. Colvocorresses).

Variations in satcllite pitch, roll and yaw all generate non-systematic distortions that vary across the image (Sabins, 1986). The purpose of co-registration was to remove these variations and the statistical measure of the co-registration indicates that this was successful. If we assume that the ratio of the pixel sizes between the MSS and the TM is exactly $2: 1$, we can calculate the magnitude of this distortion introduced into the image by the warping process. In the southeastern part of the ice shelf, the strain introduced would be $0.5 \%$ in $x$ and $0.2 \%$ in $y$. Over 500 pixcls, the approximate distance from the control to the southeast extreme of the ice shelf in the TM image, amounts to 2.5 pixels in $x$ and 1.0 pixels in $y$. This is not sufficient to explain the differences between the profiles which occur much closer to Sobral Peninsula.

\section{CONGLUSIONS}

We have presented data on the velocity of the northern Larsen Ice Shelf during three periods, 1975-86, 1986-89 and a $15 \mathrm{~d}$ period in 1991. Significant changes in velocity 
seem to have taken place between these time periods. It is known that significant retreat of the ice shelf occurred over this time interval (Skvarca, 1993). The pattern of accelerations from 1975 to 1989 suggests that the velocity changes were not driven by the rctrcat of the ice shelf. The greatest acceleration during this period was in the section of the ice shelf fed by the glacier between Fothergill Point and Cape Worsley, not in that section farther north experiencing the greatest ice-front retreat. Acceleration of the ice might be caused by warmer temperatures occurring in the Antarctic Peninsula rcgion. The acceleration might also be accompanied by thinning which could, in turn, be responsible for the retreat of the ice front.

T'he difference between the 1986-89 image-derived velocities and the velocities of the 1991 surface survey, taken at face value, indicate a deceleration of the ice as the ice front retreated. If these changes are real, then the northern Larsen Ice Shelf is undergoing dramatic oscillations in flow rate. We hope to obtain more highresolution imagery that avoids the control limitations of the TM image used in this paper and spans the time period of the ground survey. In addition, the ground survey should be repeated with a longer time base and bc closed on rock, as was the second of the surveys discussed here, to constrain more tightly that data set. When these two additions to the data set are complete, some of the unresolved questions posed in this paper will be answered.

\section{ACKNOWLEDGEMENT}

This work was supported by U.S. National Science Foundation grant DPP-9018127.

\section{REFERENCES}

Doake, C.S. M. and D. G. Vaughan. 1991, Rapid disintegration of the Wordic Ice Shelf in response to atmospheric warming. Vature. $\mathbf{3 5 0}(6316), 328-330$

Fahnestock, M. A., T.A. Scambos and R. A. Bindschadler. 1992. Semiautomated ice velocity determination from satellite imagery. EOS, $73(43), 493$.

Morrison, S.J. 1990. Warmest year on record on the Antarctic Peninsula? Weather, 45(6), 231-232.

Sabins, F. F. 1986. Remete sensing, principles and interpretation. Second edition. New York, W. H. Freeman and Co.

Scambos, T. A., M. J. Dutkicwicz, J. C. Wilson and R. A. Bindschadler. 1992. Application of image cross-correlation to the measurement of glacier velocity using satellite image data. Remote Sensing Eniron., $42(3), 177-186$.

Skvarca, P. 1993. Fast recession of the northern Larsen Ice Shelf monitored by space images, Anm. Glaciol., 17, 317321.

The accuracy of references in the lext and in this list is the responsibility of the authors, to whom queries should be addressed. 